\title{
Determination of the antioxidant capacity, total phenolic and flavonoid contents of seeds from three commercial varieties of culinary dates
}

\author{
Jacopo Mistrello $^{a}$, Sameera D. Sirisena ${ }^{b}$, Abdollah Ghavami ${ }^{*}$, Richard J. \\ MARSHALL $^{\mathrm{d}}$, AND SURESH KRISHNAMOORTHY ${ }^{\mathrm{c}}$ \\ ${ }^{\mathrm{a}}$ Kerry Ingredients and Flavours, Hawthorn House, Millennium Business Park, Naas, Co. Kildare, Ireland \\ b Melbourne School of Land and Environment, University of Melbourne, Building 142, Parkville Campus, \\ Parkville 3010 VIC, Australia \\ ${ }^{\mathrm{c}}$ School of Human Sciences, Faculty of Life Sciences and Computing, London Metropolitan University, 166-220 \\ Holloway Road, London N7 8DB, UK \\ ${ }^{\mathrm{d}}$ School of Society, Enterprise and Environment, Bath Spa University, Newton Park, Bath BA2 9BN, UK \\ ${ }^{*}$ Corresponding author \\ a.ghavami@londonmet.ac.uk \\ TEL: +44 (0)207 1334545 \\ FAX: $+44(0) 2071334149$
}

Received: 20 June 2013; Published online: 18 April 2014

\begin{abstract}
Date seeds are a major waste product of the date industry that could offer potentially valuable material for the production of useful food ingredients. The aim of the present study was to investigate the seeds of three date varieties of the UK market (Deglet Nour, Khouat Allig, and Zahidi) for their proximate composition, total phenolic (TPC), total flavonoid (TFC) contents and total antioxidant capacity (TAC) with a view to their eventual industrial application. Carbohydrates were present in

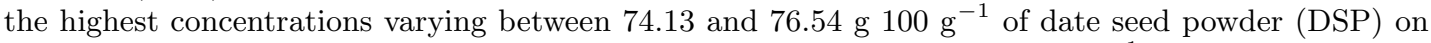

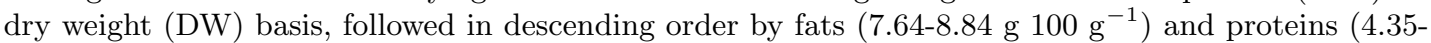

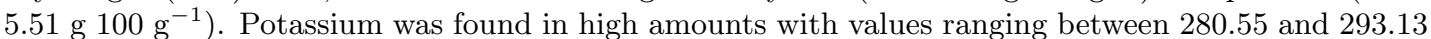
$\mathrm{mg} 100 \mathrm{~g}^{-1}$. The majority of the total phenolic content (2058-2984 mg GAE $100 \mathrm{~g}^{-1}$ ) was assumed to be composed of flavonoids (1271-1932 mg CAE $100 \mathrm{~g}^{-1}$ ). These families of dietary phenolics may be the major ones responsible for the high antioxidant capacity reported in date seeds, which varied from 12540 and $27699 \mu \mathrm{mol}$ TE $100 \mathrm{~g}^{-1}$. These results suggest that date seeds can be considered a potential raw material for natural, active ingredients for food applications as well as an unexplored source of novel nutraceuticals and dietary supplements.
\end{abstract}

Keywords: Date seeds; Pheonix dactylifera L.; ORAC; Phenolic compounds; Flavonoids, Antioxidant capacity 
Antioxidants in date seeds $\mid 35$

\author{
Abbreviations \\ AAPH: 2,2'-azobis (2-methylpropionamidine) dihydrochloride \\ AUC: area under curve \\ BP: boiling point \\ CAE: catechin equivalents \\ DSP: date seed powder \\ DW: dry weight \\ ESC: equivalent standard concentration \\ FW: fresh weight \\ GAE: gallic acid equivalents \\ ORAC: oxygen radical absorbance capacity \\ $\mathrm{R}^{2}$ : regression coefficient \\ SD: standard deviation \\ TAC: total antioxidant capacity \\ TE: trolox equivalents \\ TFC: total flavonoid content \\ TPC: total phenolic content \\ Trolox $^{\text {TM }}$ : 6-hydroxy-2,5,7,8-tetramethylchroman-2-carboxylic acid \\ SFCA : surfactant-free cellulose acetate \\ DMSO : dimethyl sulfoxide
}

\section{Introduction}

The processing of many foods generates waste residues and by-products that can be converted into useful ingredients. The potential benefits of exploiting food waste, which includes enhanced profitability and reduction of environmental pollution, has prompted intensified research in this area and more information is now available on fruit sources from various food processing industries (Balasundram, Sundram, \& Samman, 2006; Roldan, Sanchez-Moreno, de Ancos, \& Cano, 2008; Wijngaard, Roessle, \& Brunton, 2009; Esquivel \& Jimenez, 2012). The fruits of the date palm (Phoenix dactylifera L.) are another suitable example. The worldwide production of dates has steadily grown over the last decade and has reached 7.9 million tonnes (FAO, 2012). This has been beneficial to the underdeveloped areas where date palms are most commonly cultivated (Aleid, 2011) as it has brought new opportunities for social and economic growth. However, the consequent expansion of the date processing industry has also led to the generation of greater amounts of waste (Mistrello, 2012).

Date seeds account for up to $10-15 \%$ of the total fruit weight and represent a major waste mate- rial of the date industry. According to recent estimates up to 800,000 tonnes/year of seeds could be disposed of (Al-Farsi \& Lee, 2008), although a very small fraction of this is used locally for animal feed (Devshony, Eteshola, \& Shani, 1992; Al-Farsi \& Lee, 2008). However, new findings on their nutritional and phytochemical profile have demonstrated their potential use as natural active extracts and functional ingredients in food and non-food applications (Besbes, Blecker, Deroanne, Drira, \& Attia, 2004; Al-Farsi \& Lee, 2008; Juhaimi, Ghafoor, \& Ozcan, 2012). Our previous research has also shown the possible utilisation of date seeds for new product development concepts (Mistrello, 2013). In that study, an infusion made of date seed powder was developed and compared in terms of phenolic content to some high-antioxidant beverages giving positive results. Other studies have also revealed much higher amounts of such compounds in date seeds as compared to the corresponding flesh (AlFarsi et al., 2007), increasing the general interest in this waste material and particularly in its potential application in the food industry. The nutritional and phytochemical content of date seeds from different geographic origins are now well established (Al-Shahib \& Marshall, 2003; Al- 
36 Mistrello et al.

Farsi et al., 2007; Habib \& Ibrahim, 2009). Despite this, only a little information is so far available on their flavonoid fraction (Al-Farsi \& Lee, 2008), and total antioxidant capacity by Oxygen Radical Absorbance Capacity (ORAC). Thus, the purposes of the present study were to determine the proximate composition, TPC, TFC, and TAC (by ORAC) of date seeds from commercial varieties available in the United Kingdom, with a view to their eventual use as by-products.

\section{Materials and Methods}

\subsection{Chemicals}

Methanol (HPLC grade), acetone (HPLC grade), Kjeldahl catalyst tablets, sulfuric acid (analytical grade), acetic acid ( $\geq 99.0 \%)$, nitric acid (analytical grade), hydrogen peroxide (35\% in water, stabilized), petroleum ether (BP 40-60 ${ }^{\circ} \mathrm{C}$, analytical grade), and the calcium $(\mathrm{Ca})$, iron $(\mathrm{Fe})$, magnesium $(\mathrm{Mg})$, and potassium (K) standard solutions $\left(1000 \pm 5 \mathrm{mg} \mathrm{L}^{-1}\right.$ in nitric acid) were purchased from Fisher Scientific UK Ltd (Loughborough, UK). FolinCiocalteu phenol reagent (Fluka), gallic acid analytical standard ( $\geq 97.9 \%$, Fluka) catechin analytical standard ( $\geq 99.0 \%$, Fluka), aluminum chloride anhydrous $(\geq 99.0 \%$, Fluka), sodium hydroxide anhydrous $(\geq 98.0 \%)$, sodium phosphate dibasic dihydrate, sodium phosphate monobasic dihydrate, 6-carboxyfluorescein, 2,2'azobis (2-methylpropionamidine) dihydrochloride (AAPH) and Trolox ${ }^{\text {TM }}$ (6-hydroxy-2,5,7,8tetramethylchroman-2-carboxylic acid) (Fluka) were purchased from Sigma-Aldrich Co. (Poole, UK). Sodium carbonate anhydrous ( $\geq 99 \%$ ), sodium nitrite $(\geq 99.5 \%)$, the manganese $(\mathrm{Mn})$ and sodium $(\mathrm{Na})$ standard solutions $(1001 \pm 5$ $\mathrm{mg} \mathrm{L}^{-1}$ and $1000 \pm 5 \mathrm{mg} \mathrm{L}^{-1}$ in nitric acid, respectively) were purchased from BDH Laboratory Supplies (Poole, UK).

\subsection{Preparation of date seed powder (DSP)}

Dates from three varieties as shown in Fig. 1., namely Zahidi (Iran), Deglet Nour (Tunisia), and Khouat Allig (Tunisia) were purchased in local supermarkets and stored at $4{ }^{\circ} \mathrm{C}$ until use. About $200 \mathrm{~g}$ of seeds were separated from the fruits of each variety, soaked in water to remove any residual flesh and air dried for $24 \mathrm{~h}$ at room temperature. Five seeds from each variety were randomly selected to assess the relative weight and the rest was milled separately in a domestic coffee grinder. The resulting powders were screened through a $2 \mathrm{~mm}$ mesh sieve to obtain a homogeneous fraction. Batches of $10 \mathrm{~g}$ of DSP were collected in specimen tubes and stored at $-20{ }^{\circ} \mathrm{C}$ prior to analysis. For determination of moisture, TPC, TFC and TAC, fresh DSP was used. For all the other analyses, dry DSP was used. This approach was followed to prevent degradation of phenolic compounds during drying (Sultana, Anwar, Ashraf, \& Saari, 2012). All analyses were performed in triplicate.

\subsection{Proximate determination}

Moisture was determined by oven drying for seven hours to constant weight in an air oven at $105^{\circ} \mathrm{C}$ and ash by combustion at $550{ }^{\circ} \mathrm{C}$ (AOAC, 1990). Total nitrogen was determined in a Foss digestion system and automatic analyzer (Kjeltec 2300; Foss Ltd, Warrington, UK). Protein content was calculated from total nitrogen using the general factor 6.25 (Besbes et al., 2004). Fat was determined by extracting $2 \mathrm{~g}$ of DSP in $75 \mathrm{~mL}$ of petroleum ether $\left(40-60{ }^{\circ} \mathrm{C}\right)$ in a Soxtec extraction system (Foss Ltd) for $3 \mathrm{~h}$. Total carbohydrates were estimated by difference (AlFarsi et al., 2007). All proximate values (except moisture) were expressed as g $100 \mathrm{~g}^{-1}$ of DSP on DW basis. The mineral constituents $(\mathrm{Ca}, \mathrm{Fe}$, $\mathrm{Mg}, \mathrm{Mn}, \mathrm{Na}$, and $\mathrm{K}$ ) of each variety were analyzed separately using a SpectrAA 220 atomic absorption spectrophotometer (Varian Inc., Palo Alto, USA). For this determination, the samples were prepared by wet oxidation (AOAC, 1990). The content of each mineral was expressed as $\mathrm{mg}$ $100 \mathrm{~g}^{-1}$ of DSP on DW basis. 


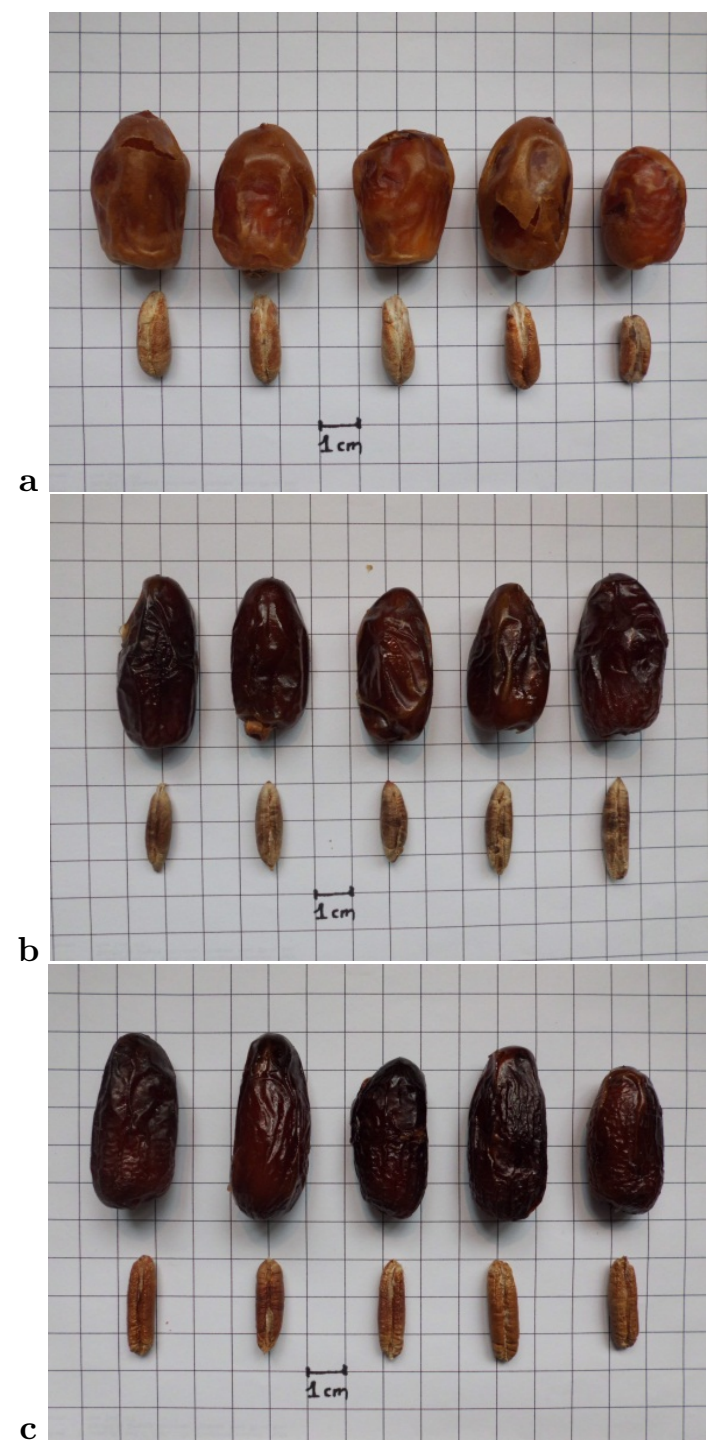

Figure 1: Photos of date fruit and seeds: a) Zahidi b) Deglet Nour c) Khouat Allig.

\subsection{Extraction method for TPC and TFC}

For quantification of TPC and TFC, a solution of acetone:water $(50: 50, \mathrm{v} / \mathrm{v})$ was used for its high extraction yields (Al-Farsi \& Lee, 2008) as shown by in-house tests (data not shown). Aliquots of $1 \mathrm{~g}$ of DSP were dispersed in $20 \mathrm{~mL}$ of the acetone:water solution and extracted for $2 \mathrm{~h}$ at $200 \mathrm{rpm}$ in an Innova 43 orbital shaker at room temperature (New Brunswick Scientific, Enfield, USA). The supernatants were separated from the solid residues at $552 \mathrm{~g}$ for $5 \mathrm{~min}$ in a bench-top centrifuge (Denley Ltd, Heckmondwike, UK). Clear extracts were then obtained by double-filtration, firstly through Whatman No. 4 filter papers, and then through a surfactant-free cellulose acetate (SFCA) syringe filters (Corning Inc., Corning, USA). Samples were stored at $4{ }^{\mathrm{o}} \mathrm{C}$, and analyzed within four days. On the day of the determination all the extracts were diluted ten-fold in the same solvent solution prior to analysis.

\subsection{Total phenolic content (TPC)}

The total phenolic content was estimated using the Folin-Ciocalteu assay (Saafi, El Arem, Issaoui, Hammami, \& Achour, 2009). Aliquots of $200 \mu \mathrm{L}$ were thoroughly mixed with $1.5 \mathrm{~mL}$ of Folin-Ciocalteu phenol reagent (previously diluted 1:10 in water), and allowed to stand for 5 min. To this was added $1.5 \mathrm{~mL}$ of sodium carbonate ( $60 \mathrm{~g} \mathrm{~L}^{-1}$ in water) and the mixture was gently swirled. After incubation (90 min at room temperature), the absorbance was measured at $725 \mathrm{~nm}$ on a UV-1800 spectrophotometer (Shimadzu, Kyoto, Japan). Readings were calibrated using known concentrations of gallic acid (9.4, 37.6, 94, 188, $\left.470 \mathrm{mg} \mathrm{L}^{-1}\right)$ in the solvent solution. The highest standard concentration was diluted ten-fold prior to analysis to ensure a correct reading. A blank consisting of water instead of the extract was prepared as above and used to set the zero on the spectrophotometer prior to each determination. TPC was expressed as $\mathrm{mg}$ of gallic acid equivalents (GAE) per $100 \mathrm{~g}$ of DSP on fresh weight (FW) basis. 


\subsection{Total flavonoid content (TFC)}

The total flavonoid content was determined according to Al-Farsi and Lee, 2008. Briefly, $1 \mathrm{~mL}$ of extract was dissolved in $5 \mathrm{~mL}$ of water in a 10 $\mathrm{mL}$ volumetric flask. To this $0.3 \mathrm{~mL}$ of sodium nitrite $\left(50 \mathrm{~g} \mathrm{~L}^{-1}\right.$ in water) was added; the mixture was allowed to stand for $5 \mathrm{~min}$ and then $0.3 \mathrm{~mL}$ of aluminum chloride $\left(100 \mathrm{~g} \mathrm{~L}^{-1}\right.$ in water) was added. The mixture was incubated $(6$ min at room temperature), after which $2 \mathrm{~mL}$ of sodium hydroxide (1 $\mathrm{M}$ in water) was added and diluted to volume with water. The absorbance was immediately measured at $510 \mathrm{~nm}$. Measurements were calibrated with a standard curve of known concentrations of catechin $(46.4,116,232$, $462 \mathrm{mg} \mathrm{L}^{-1}$ ) in the solvent solution. The highest standard concentration was diluted ten-fold prior to analysis to ensure a correct reading. A blank consisting of water instead of the extract was prepared as above. TFC was expressed as $\mathrm{mg}$ of catechin equivalents (CAE) per $100 \mathrm{~g}$ of DSP on FW basis.

\subsection{Oxygen Radical Absorbance Capacity $(O R A C)$ assay}

For determination of TAC, $0.5 \mathrm{~g}$ of DSP was extracted with $20 \mathrm{~mL}$ of acetone:water (50:50, $\mathrm{v} / \mathrm{v}$ ) firstly by vortex mixing for $1 \mathrm{~min}$ and then by mixing in an orbital shaker for $1 \mathrm{~h}$ at 200 rpm $\left(2{ }^{\circ} \mathrm{C}\right)$. The solvent was selected on the basis of its high extraction yields for date flesh (Al-Farsi, Alasalvar, Morris, Baron, \& Shahidi, 2005) and supported by in-house tests (data not shown). The mixtures were centrifuged at 4969 $g$ for $30 \mathrm{~min}$ and then the supernatants were collected and stored at $-4{ }^{\mathrm{O}} \mathrm{C}$ until analysis. The ORAC assay was performed according to (Fegredo, Wong, Wiseman, \& Preedy, 2009) using 6carboxyfluorescein as the fluorescence probe and AAPH as the free radical generator. A Fluostar
Omega multi-mode microplate reader (BMGLabtech, Ortenburg, Germany), with Corning ${ }^{\circledR}$ 96 well black round bottom micro-plate (Corning Inc., Corning, USA) was used. Fluorescence was measured every 2 min for a total of $2 \mathrm{~h}$ at $37^{\mathrm{o}} \mathrm{C}$ using excitation and emission wavelengths of $485 \mathrm{~nm}$ and $520 \mathrm{~nm}$ respectively. The Trolox regression curve $\left(R^{2}=0.998\right)$ was used to assess the Equivalent Standard Concentration (ESC); this latter parameter was then applied to Equation 1, and the final total antioxidant capacity, expressed as Trolox equivalents (TE) per $100 \mathrm{~g}$ of DSP on FW basis, was calculated.

\subsection{Statistical analysis}

Minitab Statistical Software 16.0 (Minitab Inc., State College, USA) was used to perform all statistical analyses. Data were subject to one-way ANOVA and significant differences were evaluated using Tukey's multiple range test. Results were reported as means \pm standard deviations (SD). Differences at $\mathrm{P} \leq 0.05$ were considered significantly different.

\section{Results and discussion}

\subsection{Seed weight and proximate composition}

The weight, nutritional and mineral composition, total phenolic and flavonoid contents, and total antioxidant capacity of date seeds are shown in Table 1. The relative seed weight ranged from

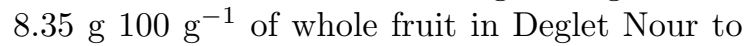

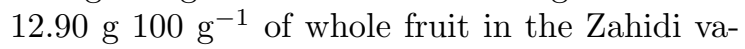
riety. The carbohydrate fraction varied between

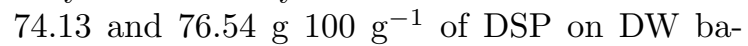
sis. Higher amounts of total carbohydrates were reported by Besbes et al., 2004 in the seeds of Deglet Nour and Allig varieties from Tunisia (81-83

$$
\mu \text { mol TE per } 100 \mathrm{~g}=\frac{E S C \times \text { Dilution Factor }}{\text { Initial weight of the sample / Volume of extract in litres }} \times 100
$$


Antioxidants in date seeds $\mid 39$

Table 1: Proximate composition, total phenolic (TPC), total flavonoid content (TFC), and total antioxidant capacity (TAC) of date seed powders (DSP)

\begin{tabular}{|c|c|c|c|}
\hline & Zahidi & Deglet Nour & Khouat Allig \\
\hline Seed Weight, \% of total fruit weight & 12.90 & 8.35 & 11.22 \\
\hline \multicolumn{4}{|l|}{ Proximate composition } \\
\hline $\begin{array}{l}\text { Moisture, } \\
\text { g per } 100 \mathrm{~g} \text { of DSP fresh weight basis }\end{array}$ & $10.26 \pm 0.23^{a}$ & $10.21 \pm 0.18^{a}$ & $9.95 \pm 0.15^{a}$ \\
\hline $\begin{array}{l}\text { Ash, } \\
\text { g per } 100 \mathrm{~g} \text { of DSP dry weight basis }\end{array}$ & $1.25 \pm 0.01^{a}$ & $1.24 \pm 0.09^{a}$ & $1.18 \pm 0.06^{a}$ \\
\hline $\begin{array}{l}\text { Protein, } \\
\text { g per } 100 \mathrm{~g} \text { of DSP dry weight basis }\end{array}$ & $5.51 \pm 0.34^{a}$ & $4.35 \pm 0.39^{b}$ & $4.68 \pm 0.37^{a b}$ \\
\hline $\begin{array}{l}\text { Fat, } \\
\text { g per } 100 \mathrm{~g} \text { of DSP dry weight basis }\end{array}$ & $8.84 \pm 0.23^{a}$ & $8.74 \pm 0.12^{a}$ & $7.64 \pm 0.20^{b}$ \\
\hline $\begin{array}{l}\text { Total carbohydrate, } \\
\mathrm{g} \text { per } 100 \mathrm{~g} \text { of DSP dry weight basis }\end{array}$ & $74.13 \pm 0.65^{b}$ & $75.46 \pm 0.40^{a b}$ & $76.54 \pm 0.65^{a}$ \\
\hline $\begin{array}{l}\text { Mineral composition } \\
\text { Ca } \\
\text { mg per } 100 \mathrm{~g} \text { of DSP dry weight basis }\end{array}$ & $11.32 \pm 0.86^{a}$ & $12.34 \pm 0.44^{a}$ & $12.87 \pm 0.83^{a}$ \\
\hline $\begin{array}{l}\text { Fe } \\
\text { mg per } 100 \mathrm{~g} \text { of DSP dry weight basis }\end{array}$ & $2.49 \pm 0.26^{b}$ & $0.51 \pm 0.04^{c}$ & $4.00 \pm 0.23^{a}$ \\
\hline $\begin{array}{l}\mathrm{Mg} \\
\text { mg per } 100 \mathrm{~g} \text { of DSP dry weight basis }\end{array}$ & $44.71 \pm 0.22^{b}$ & $44.52 \pm 0.22^{b}$ & $47.60 \pm 0.27^{a}$ \\
\hline $\begin{array}{l}\text { Mn } \\
\text { mg per } 100 \mathrm{~g} \text { of DSP dry weight basis }\end{array}$ & $0.49 \pm 0.05^{a}$ & $0.35 \pm 0.03^{b}$ & $0.24 \pm 0.01^{c}$ \\
\hline $\begin{array}{l}\mathrm{Na} \\
\mathrm{mg} \text { per } 100 \mathrm{~g} \text { of DSP dry weight basis }\end{array}$ & $13.41 \pm 1.27^{a}$ & $10.17 \pm 0.11^{b}$ & $4.56 \pm 0.04^{c}$ \\
\hline $\begin{array}{l}\text { K } \\
\text { mg per } 100 \mathrm{~g} \text { of DSP dry weight basis }\end{array}$ & $293.13 \pm 26.96^{a}$ & $280.55 \pm 10.21^{a}$ & $290.44 \pm 2.96^{a}$ \\
\hline $\begin{array}{l}\boldsymbol{T P C} \\
\text { mg GAE per } 100 \mathrm{~g} \text { DSP fresh weight basis }\end{array}$ & $2058 \pm 38^{b}$ & $2983 \pm 91^{a}$ & $2061 \pm 116^{b}$ \\
\hline $\begin{array}{l}\boldsymbol{T F C} \\
\text { mg CAE per } 100 \mathrm{~g} \text { DSP fresh weight basis }\end{array}$ & $1425 \pm 38^{b}$ & $1932 \pm 65^{a}$ & $1271 \pm 81^{c}$ \\
\hline $\begin{array}{l}\text { TAC }(\boldsymbol{O R} \boldsymbol{A} \boldsymbol{C}) \\
\mu \mathrm{mol} \text { TE per } 100 \mathrm{~g} \text { DSP fresh weight basis }\end{array}$ & $12540 \pm 983^{b}$ & $27699 \pm 689^{a}$ & $26906 \pm 338^{a}$ \\
\hline
\end{tabular}

$\overline{\text { Data are reported to mean }(\mathrm{n}=3) \pm \text { SD. Means } \pm \text { SD followed by a different letter, within a row, }}$ are significantly different $(\mathrm{p} \leq 0.05)$. 
g $100 \mathrm{~g}^{-1}$ on DW basis), and by Al-Farsi et al., 2007 in other varieties from Oman (83-86 g 100 $\mathrm{g}^{-1}$ on FW basis). The average content of moisture and ash, which ranged from 9.95 to 10.26 g $100 \mathrm{~g}^{-1}$ of DSP on DW basis and from 1.18

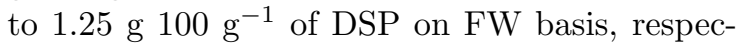
tively, is in general agreement with the literature (Hamada, Hashim, \& Sharif, 2002; Chaira, Ferchichi, Mrabet, \& Sghairoun, 2007; Habib \& Ibrahim, 2009) and showed no significant intrasample differences $(\mathrm{P}>0.05)$. With regard to the protein and fat content, significant differences were observed $(\mathrm{P} \leq 0.05)$, with the highest values detected in Zahidi seeds with 5.51 and

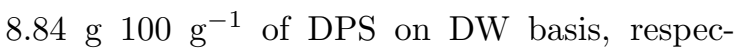
tively. Similar values were reported for Zahidi and Deglet Nour varieties from Israel (Devshony et al., 1992), whereas slightly higher amounts of proteins and fats were found by Besbes et al., 2004 and by Chaira et al., 2007 for Deglet Nour and Allig varieties from Tunisia. Date seeds also contained significant amount of minerals. Potassium was found in the highest concentration, followed in descending order by magnesium, calcium, sodium, iron, and manganese. This order and similar values were reported in Besbes et al., 2004 in analogous seed varieties, and in other varieties in Devshony et al., 1992, Chaira et al., 2007, and Habib and Ibrahim, 2009. Higher amounts of potassium ( $500 \mathrm{mg} 100 \mathrm{~g}^{-1}$, on average) were detected in the seeds of six date cultivars grown in the Bahraini region (Ali-Mohamed $\&$ Khamis, 2004). The variations reported in the present study, as well as the differences with data from previous studies could be ascribed not only to varietal factors but also to agronomic conditions and geographic origins as already suggested in Besbes et al., 2004 and Al-Farsi et al., 2007.

\subsection{Total phenolic and total flavonoid content}

Significant differences $(\mathrm{P} \leq 0.05)$ were observed among the three samples in terms of total phenolic content. The seeds from Deglet Nour variety (Tunisia) exhibited the highest TPC with an average of $2984 \mathrm{mg}$, followed by Khouat Allig (Tunisia) with $2061 \mathrm{mg}$, and Zahidi (Iran) with $2058 \mathrm{mg} \mathrm{GAE} 100 \mathrm{~g}^{-1}$ of DSP on FW basis. No data is currently available in the literature for these seeds, though higher contents of phenolics (3102-4430 mg GAE $100 \mathrm{~g}^{-1}$ ) were reported in the seeds of Omani date fruits (Al-Farsi et al., 2007), whereas much lower amounts (1.98 and $4.65 \mathrm{mg}$ GAE $100 \mathrm{~g}^{-1}$ of seeds) were shown in Saudi Arabian varieties (Juhaimi et al., 2012). Interestingly, when the polar aprotic solvent dimethyl sulfoxide (DMSO) was used higher TPCs were detected (Ardekani, Khanavi, Hajimahmoodi, Jahangiri, \& Hadjiakhoondi, 2010) in comparison to common polar solvents (water, aqueous methanol and methanol). This underlines the importance of the extraction solvent when determining TPC and TFC. The structure of phenolic compounds which varies from simple (e.g. phenolic acids) to highly polymerized forms (e.g. flavonoids, and tannins) together with other factors such as the number and position of their -OH groups, type of chemical substituents (Harborne et al., 1964), and glycosidic side groups (Gonzalez-Paramas, Santos-Buelga, Duenas, \& Gonzalez-Manzano, 2011) affects their solubility and therefore extraction yields.

Currently, only few of the total number of date varieties have been analysed for the phenolic profile of their seeds. The investigation of the phenolic acid profile of date seeds from Oman by Al-Farsi and Lee, 2008 revealed the presence of four hydroxylated derivatives of benzoic acid ( $p$ hydroxybenzoic, protocatechuic, vanillic and gallic acid) and five cinnamic acid derivatives $(m-$ coumaric, ferulic, $p$-coumaric, o-coumaric, caffeic acid), though other phenolic groups could be significant. For example, the study by Besbes et al., 2005 reported values of total phenolics ranging between 215 and $526 \mu \mathrm{g} \mathrm{g}^{-1}$ of date seed oil from Deglet Nour and Allig varieties, respectively. This reveals the presence in date seeds of an interesting apolar fraction of phenolic compounds, an area where further investigation is needed.

According to our findings, flavonoids accounted for the majority of the total phenolics, varying between $1932 \mathrm{mg}$ CAE $100 \mathrm{~g}^{-1}$ of DSP on DW basis in the Deglet Nour, and $1271 \mathrm{mg}$ CAE 100 $\mathrm{g}^{-1}$ of DSP on DW basis in Khouat Allig variety. Only Al-Farsi and Lee, 2008 have investigated this family of compounds in date seeds, but their results were expressed on seed concentrates 
Antioxidants in date seeds $\mid 41$

rather than on the raw material. Therefore, the present study provides the first insight into the TFC of date seeds and indicates they contain appreciable amounts. This approach can be used to implement the recovery and subsequent industrial processing of date seeds as natural source of these compounds with unlimited potentials in food and non-food sectors. Flavonoids, which are chemically defined as benzo- $\gamma$-pyrone derivatives and consist of phenolic and pyran rings (Heim, Tagliaferro, \& Bobilya, 2002), are in fact associated with potential bioactive properties (Heim et al., 2002; Ross \& Kasum, 2002; FernandezPanchon, Villano, Troncoso, \& Garcia-Parrilla, 2008). Their efficient use as natural colourings has been demonstrated a number of times (Bridle \& Timberlake, 1997; Espin, Soler-Rivas, Wichers, \& Garcia-Viguera, 2000), food antioxidants (Kranl et al., 2005; Capitani, Carvalho, Rivelli, Barros, \& Castro, 2009), and antimicrobial agents (Xu \& Lee, 2001; Cushnie \& Lamb, 2005). In these terms, conventional and emerging technologies such as supercritical and subcritical, microwave- and ultrasound-assisted extraction can be used to develop a tailored-made process of extracting and purifying flavonoids from date seeds; however, more studies are needed to identify the most efficient, environmentally friendly and economically feasible method.

\subsection{Total Antioxidant Capacity (TAC) - ORAC}

In this study the ORAC method was chosen since it is presently the only antioxidant capacity assay that measures the complete reaction between reactive species and antioxidants taking into account both time and degree of inhibition (Cao \& Prior, 1999; Prior, Wu, \& Schaich, 2005; Dudonne, Vitrac, Coutiere, Woillez, \& Merillon, 2009), thus it is the most recommended method for food samples where complex reaction kinetics occur (Huang, Ou, \& Prior, 2005). Significant differences were observed among the varieties investigated. The seeds of Deglet Nour and Khoaut Allig had similar values of 27698 and $26905 \mu \mathrm{mol}$ TE $100 \mathrm{~g}^{-1}$ of DSP on FW basis, whereas significantly lower amounts $(\mathrm{P} \leq 0.05)$ were detected in Zahidi $\left(12540 \mu \mathrm{mol} \mathrm{TE} 100 \mathrm{~g}^{-1}\right.$ of DSP on
Table 2: $\mathrm{R}^{2}$ values for selected ORAC assays performed using Trolox and gallic acid as standards

\begin{tabular}{ccc}
\hline Assay & $\mathbf{R}^{2}$-Trolox & $\mathbf{R}^{2}-$ Gallic Acid \\
\hline $\mathbf{1}$ & 0.998 & 0.996 \\
$\mathbf{2}$ & 0.991 & 0.994 \\
$\mathbf{3}$ & 0.993 & 0.990 \\
\hline
\end{tabular}

FW basis). According to our knowledge, only AlFarsi et al., 2007 has measured the TAC of date seeds using the ORAC assay. Although their values $\left(58000-92900 \mu \mathrm{mol}\right.$ TE $100 \mathrm{~g}^{-1}$ of seed on FW basis) were much higher than those observed in the present study, different date varieties were studied. It is reasonable to think that phenolic compounds and in particular flavonoids were the major factors responsible for the high TAC values, but other antioxidant compounds may have played a significant role.

For future studies, the use of more than one single approach for TAC determination is recommended in order to take into account the diverse mechanisms of action of antioxidants (Huang et al., 2005; Capitani et al., 2009; Dudonne et al., 2009; Tabart et al., 2012). On the other hand, there are still controversies over the significance of current in vitro techniques in predicting the in vivo effects of antioxidant compounds (Serrano, Goni, \& Saura-Calixto, 2007) and their functionality in preventing or delaying oxidation in foods (Fernandez-Panchon et al., 2008; Alamed, Chaiyasit, McClements, \& Decker, 2009). In terms of the physiological effects of their consumption, in vitro studies should be supported by in vivo clinical tests aiming to investigate specific healthpromoting activities. Moreover, in terms of their active properties further tests on actual food systems should be carried out looking at the ability of date seed extracts to counteract the formation of reactive species using appropriate techniques such as thiobarbituric acid reactive substances, lipid hydroperoxides and headspace hexanal analysis (Alamed et al., 2009).

In the course of the study gallic acid was also investigated as potential alternative to Trolox. The results for the Trolox equivalents and gallic acid equivalents TAC values obtained for the corresponding samples were not significantly different 
$42 \mid$ Mistrello et al.

$(\mathrm{P} \leq 0.05)$. In addition, the regression data of the area under curve (AUC) of the antioxidant standards Trolox and gallic acid (Table 2) showed that the latter standard has the potential to be used in ORAC assay.

\section{Conclusions}

The present study improves our knowledge of the chemical composition of date seeds, and supports their potential use as natural, active ingredients for food and non-food applications. The suitability of using date seed powders to counteract lipid oxidation and therefore maintain food quality should be assessed on complex food systems using more specific techniques. In addition, the future commercial application of such by-products as nutraceuticals or dietary supplements depends on further investigation of their in vivo health effects by means of physiologically relevant clinical tests. Lastly, the environmental and economic benefits deriving from such approaches needs to be balanced with other factors, such as the cost-effectiveness of the extraction and recovery of bioactive and nutrient constituents, marketability and standardization of the derived products and availability and cost of the raw material. The samples used for this research were opportunistic, representing those varieties that were available at the time. There was no information available on the effect of genotype, environmental conditions, cultivation, harvest and transport of the samples and the results are considered indicative rather than definitive.

\section{Acknowledgements}

The research was performed at the School of Human Sciences, Faculty of Life Sciences and Computing, London Metropolitan University, 166-220 Holloway Road, London N7 8DB, UK. We thank Brian Whiting, Osman Erkek, and Arun Rajan from London Metropolitan University staff for their technical advice and help. There are no conflicts of interest.

\section{References}

Al-Farsi, M, Alasalvar, C, Morris, A, Baron, M, \& Shahidi, F. (2005). Comparison of antioxidant activity, anthocyanins, carotenoids, and phenolics of three native fresh and sun-dried date (Phoenix dactylifera l.) varieties grown in oman. Journal of Agricultural and Food Chemistry, 53(19), 7592-7599. doi:10.1021/jf050579q

Al-Farsi, M., Alasalvar, C., Al-Abid, M., AlShoaily, K., Al-Amry, M., \& Al-Rawahy, F. (2007). Compositional and functional characteristics of dates, syrups, and their by-products. Food Chemistry, 104(3), 943947. doi:10.1016/j.foodchem.2006.12.051

Al-Farsi, M. A., \& Lee, C. Y. (2008). Optimization of phenolics and dietary fibre extraction from date seeds. Food Chemistry, 108(3), 977-985. doi:10.1016/j.foodchem. 2007.12.009

Al-Shahib, W, \& Marshall, R. (2003). Fatty acid content of the seeds from 14 varieties of date palm Phoenix dactylifera l. International Journal of Food Science and Technology, 38(6), 709-712. doi:10.1046/j.13652621.2003.00723.x

Alamed, J., Chaiyasit, W., McClements, D. J., \& Decker, E. A. (2009). Relationships between free radical scavenging and antioxidant activity in foods. Journal of Agricultural and Food Chemistry, 57(7), 29692976. doi:10.1021/jf803436c

Aleid, S. (2011). Industrial biotechnology: date palm fruit applications. In S. M. Jain, J. M. Al-Khayri \& D. V. Johnson (Eds.), Date palm biotechnology (pp. 675-709). Springer Netherlands. doi:10 . 1007 / 978 - 94 - 007 1318-5_32

Ali-Mohamed, A., \& Khamis, A. (2004). Mineral ion content of the seeds of six cultivars of bahraini date palm (Phoenix dactylifera). Journal of Agricultural and Food Chemistry, 52(21), 6522-6525. doi:10.1021 / jf035018x

AOAC. (1990). Official methods of analysis (14th ed.) Washington, DC: Association of Official Analytical Chemists.

Ardekani, M. R. S., Khanavi, M., Hajimahmoodi, M., Jahangiri, M., \& Hadjiakhoondi, A. 
Antioxidants in date seeds $\mid 43$

(2010). Comparison of antioxidant activity and total phenol contents of some date seed varieties from iran. Iranian Journal of Pharmaceutical Research, 9(2), 141-146.

Balasundram, N, Sundram, K, \& Samman, S. (2006). Phenolic compounds in plants and agri-industrial by-products: antioxidant activity, occurrence, and potential uses. Food Chemistry, 99(1), 191-203. doi:10.1016/j. foodchem.2005.07.042

Besbes, S, Blecker, C, Deroanne, C, Drira, N., \& Attia, H. (2004). Date seeds: chemical composition and characteristic profiles of the lipid fraction. Food Chemistry, 84(4), 577584. doi:10.1016/S0308-8146(03)00281-4

Besbes, S, Blecker, C, Deroanne, C, Lognay, G, Drira, N., \& Attia, H. (2005). Heating effects on some quality characteristics of date seed oil. Food Chemistry, 91(3), 469-476. doi:10.1016/j.foochem.2004.04.037

Bridle, P, \& Timberlake, C. (1997). Anthocyanins as natural food colours - selected aspects. Food Chemistry, 58(1-2), 103-109. doi:10.1016/S0308-8146(96)00222-1

Cao, G., \& Prior, R. (1999). Measurement of oxygen radical absorbance capacity in biological samples. In Oxidants and antioxidants, pt a (Vol. 299, pp. 50-62). METHODS IN ENZYMOLOGY.

Capitani, C. D., Carvalho, A. C. L., Rivelli, D. P., Barros, S. B. M., \& Castro, I. A. (2009). Evaluation of natural and synthetic compounds according to their antioxidant activity using a multivariate approach. European Journal of Lipid Science and Technology, 111(11), 1090-1099. doi:10.1002/ejlt. 200800215

Chaira, N., Ferchichi, A., Mrabet, A., \& Sghairoun, M. (2007). Chemical composition of the flesh and the pit of date palm fruit and radical scavenging activity of their extracts. Retrieved from http:// http://docsdrive.com/pdfs/ansinet/pjbs / 2007/2202-2207.pdf

Cushnie, T., \& Lamb, A. (2005). Antimicrobial activity of flavonoids. International Journal of Antimicrobial Agents, 26(5), 343356. doi:10.1016/j.ijantimicag.2005.09.002

Devshony, S., Eteshola, E., \& Shani, A. (1992). Characteristics and some potential applica- tions of date palm (Phoenix-dactylifera L) seeds and seed oil. Journal of the American Oil Chemists Society, 69(6), 595-597. doi:10.1007/BF02636115

Dudonne, S., Vitrac, X., Coutiere, P., Woillez, M., \& Merillon, J.-M. (2009). Comparative study of antioxidant properties and total phenolic content of 30 plant extracts of industrial interest using dpph, abts, frap, sod, and orac assays. Journal of Agricultural and Food Chemistry, 57(5), 17681774. doi:10.1021/jf803011r

Espin, J., Soler-Rivas, C, Wichers, H., \& GarciaViguera, C. (2000). Anthocyanin-based natural colorants: a new source of antiradical activity for foodstuff. Journal of Agricultural and Food Chemistry, 48(5), 1588 1592. doi:10.1021/jf9911390

Esquivel, P., \& Jimenez, V. M. (2012). Functional properties of coffee and coffee by-products. Food Research International, 46(2, SI), 488-495. doi:10.1016/j.foodres. 2011.05 .028

FAO. (2012). Statistical database. Retrieved from http://faostat.fao.org

Fegredo, J., Wong, M., Wiseman, H., \& Preedy, V. (2009). In preedy, v.r. (eds.). beer in health and disease prevention. In Manual and robotic methods for measuring the total antioxidant capacity of beers (pp. 9911002). London: Elsevier.

Fernandez-Panchon, M. S., Villano, D., Troncoso, A. M., \& Garcia-Parrilla, M. C. (2008). Antioxidant activity of phenolic compounds: from in vitro results to in vivo evidence. Critical Reviews in Food Science and Nutrition, 48(7), 649-671. doi:10. $1080 / 10408390701761845$

Gonzalez-Paramas, A. M., Santos-Buelga, C., Duenas, M., \& Gonzalez-Manzano, S. (2011). Analysis of flavonoids in foods and biological samples. Mini-Reviews in Medicinal Chemistry, 11(14), 1239-1255.

Habib, H. M., \& Ibrahim, W. H. (2009). Nutritional quality evaluation of eighteen date pit varieties. International Journal of Food Sciences and Nutrition, 60, 99-111. doi:10. 1080/09637480802314639

Hamada, J., Hashim, I., \& Sharif, F. (2002). Preliminary analysis and potential uses of date 
pits in foods. Food Chemistry, 76(2), 135137. doi:10.1016/S0308-8146(01)00253-9

Harborne, J. B. (1964). Biochemistry of phenolic compounds. (1st ed.)

Heim, K., Tagliaferro, A., \& Bobilya, D. (2002). Flavonoid antioxidants: chemistry, metabolism and structure-activity relationships. Journal of Nutritional Biochemistry, 13(10), 572-584. doi:10 . 1016 / S0955 2863(02)00208-5

Huang, D., Ou, B., \& Prior, R. (2005). The chemistry behind antioxidant capacity assays. Journal of Agricultural and Food Chemistry, 53(6), 1841-1856. doi:10.1021/ jf030723c

Juhaimi, F. A. L., Ghafoor, K., \& Ozcan, M. M. (2012). Physical and chemical properties, antioxidant activity, total phenol and mineral profile of seeds of seven different date fruit (Phoenix dactylifera 1.) varieties. International Journal of Food Sciences and Nutrition, 63(1), 84-89. doi:10. 3109/09637486.2011.598851

Kranl, K, Schlesier, K, Bitsch, R, Hermann, H, Rohe, M, \& Bohm, V. (2005). Comparing antioxidative food additives and secondary plant products - use of different assays. Food Chemistry, 93(1), 171-175. doi:10 . 1016/j.foodchem.2004.11.012

Mistrello, J. (2013). Date seeds: functional ingredient for npd. Food Science and Technology Journal, 26(4), 10-12.

Mistrello, J. (2012). The date industry: new frontiers for its sustainable development. Unpublished Poster presented at the $4^{\text {th }}$ International Forum on Food and Nutrition, Milano, Italy.

Prior, R., Wu, X., \& Schaich, K. (2005). Standardized methods for the determination of antioxidant capacity and phenolics in foods and dietary supplements. Journal of Agricultural and Food Chemistry, 53(10), 42904302. 1st International Congress on Antioxidant Methods, Orlando, FL, JUN 16-19, 2004. doi:10.1021/jf0502698

Roldan, E., Sanchez-Moreno, C., de Ancos, B., \& Cano, M. P. (2008). Characterisation of onion (Allium cepa l.) by-products as food ingredients with antioxidant and antibrowning properties. Food Chemistry,
108(3), 907-916. doi:10.1016/j.foodchem. 2007.11.058

Ross, J., \& Kasum, C. (2002). Dietary flavonoids: bioavailability, metabolic effects, and safety. Annual Review of Nutrition, 22, 19-34. doi:10.1146/annurev.nutr. 22.111401.144957

Saafi, E. B., El Arem, A., Issaoui, M., Hammami, M., \& Achour, L. (2009). Phenolic content and antioxidant activity of four date palm (Phoenix dactylifera 1.) fruit varieties grown in tunisia. International Journal of Food Science and Technology, 44 (11), 2314-2319. doi:10.1111/j.13652621.2009.02075.x

Serrano, J., Goni, I., \& Saura-Calixto, F. (2007). Food antioxidant capacity determined by chemical methods may underestimate the physiological antioxidant capacity. Food Research International, 40(1), 1521. doi:10.1016/j.foodres.2006.07.010

Sultana, B., Anwar, F., Ashraf, M., \& Saari, N. (2012). Effect of drying techniques on the total phenolic contents and antioxidant activity of selected fruits. Journal of Medicinal Plants Research, 6(1), 161-167. doi:10. 5897/jmpr11.916

Tabart, J., Franck, T., Kevers, C., Pincemail, J., Serteyn, D., Defraigne, J.-O., \& Dornmes, J. (2012). Antioxidant and antiinflammatory activities of ribes nigrum extracts. Food Chemistry, 131(4), 1116-1122. doi:10.1016/j.foodchem.2011.09.076

Wijngaard, H. H., Roessle, C., \& Brunton, N. (2009). A survey of irish fruit and vegetable waste and by-products as a source of polyphenolic antioxidants. Food Chemistry, 116(1), 202-207. doi:10.1016/j.foodchem. 2009.02 .033

Xu, H., \& Lee, S. (2001). Activity of plant flavonoids against antibiotic-resistant bacteria. Phytotherapy Research, 15(1), 39-43. doi:10 . 1002/1099-1573(200102) 15:1〈39:: AID-PTR684>3.0.CO;2-R 